\title{
Research
}

Luc G Gidding, Mark Spigt, Bjorn Winkens, Odette Herijgers and Geert-Jan Dinant

\section{PsyScan e-tool to support diagnosis and management of psychological problems in general practice:}

\author{
a randomised controlled trial
}

\begin{abstract}
Background

GPs are crucial in adequately diagnosing and initiating appropriate management for patients with psychological problems, but face many challenges and require support.
\end{abstract}

Aim

To determine the effects of the e-tool PsyScan.

\section{Design and setting}

A randomised controlled trial with a 1-year followup, comparing care using PsyScan with usual care for psychological problems, was undertaken in 10 multidisciplinary primary healthcare centres in Eindhoven, the Netherlands.

\section{Method}

Between consultations with their GP. participants in the intervention group could complete PsyScan The e-tool consists of a distress screener and Four-Dimensional Symptom Questionnaire to differentiate between stress, depression, anxiety, and somatisation symptoms, and to explore symptom severity. PsyScan generated diagnostic and therapeutic advice for GPs and participants that was automatically transferred to each patient's electronic medical record. The primary outcome was the proportion of participants that achieved a successful treatment result; namely, a decrease of $\geq 50 \%$ on the Symptom Checklist-90Revised, after 1 year.

\section{Results}

There were 176 participants in the intervention group and 160 in the control group. After multiple imputation, the participants in the intervention group had higher chances of achieving a successful treatment result compared with those in the control group lodds ratio [OR] 2.7, 95\% confidence interval $[\mathrm{Cl}]=1.5$ to $4.8, P=0.002$. Quality of life was higher in the intervention group at 12 months Imean difference in EuroQol 5 Dimensions 5 Levels index values was 0.076 , $95 \% \mathrm{Cl}=0.015$ to $0.136, P=0.01 \mathrm{l}$. The mean 1-year costs per participant were similar (€13 622 in intervention group, $€ 12487$ in control group $\left.\left[\beta=-0.03, P=0.71, R^{2}=0.05\right]\right]$.

\section{Conclusion}

PsyScan generated clinically relevant and statistically significant effects, and could be useful in offering effective individualised care to patients.

\section{Keywords}

general practice; mental health; patient portals psychosocial support systems; randomised controlled trial.

\section{INTRODUCTION}

Globally, psychological problems are among the major threats to people's health, healthcare systems, and the controllability of healthcare costs. ${ }^{1-3}$ Most patients with psychological problems first present in general practice, ${ }^{4,5}$ so it is crucial to correctly diagnose them and initiate appropriate management in that setting.

Numerous issues in general practice regarding patients with psychological problems have been described, including under- and overdiagnosis, no assessment of symptom severity, no use of standardised instruments, diagnostic and therapeutic uncertainty, and management inadequacy., ${ }^{4,6-13}$ As such, there is a need for tools that can support GPs with the diagnosis and management of patients who present with psychological problems. Several internet-based tools already exist and have been described and evaluated; these showed increased effectiveness and efficacy for achieving reliable diagnostic results, positive effects on recognition and diagnosis, higher response and remission rates, less polypharmacy, fewer medication side effects, greater satisfaction with treatment, and higher quality of life (QOL). ${ }^{14-}$ 27 However, the authors felt that some essential components were missing in the available tools, including:

- being based on the perceived needs of healthcare providers and patients;

LG Gidding, MD, PhD candidate in family practice: M Spigt, PhD, associate professor of family practice; B Winkens, PhD, associate professor of statistics and methodology; G-J Dinant. PhD, MD, professor of family practice, Care and Public Health Research Institute, Maastricht University, the Netherlands. 0 Herijgers, MD, GP, the Eindhoven Corporation of Primary Health Care Centres, the Netherlands.

Address for correspondence

Luc Gidding. P. Debyeplein 1, 6229 HA Maastricht,
- coverage of the broad range of psychological problems, instead of focusing on one specific problem;

- pragmatism in daily practice;

- translation of diagnostic information into therapeutic options; and

- facilitation of data registration in routinely used electronic medical records (EMRs). ${ }^{14-27}$

As a result, together with a multidisciplinary team of health professionals and patients, the authors developed PsyScan. Its clinical effects were evaluated, based on the hypothesis that its use would lead to more appropriate management of patients and better health in general practice.

\section{METHOD}

\section{Design}

PsyScan is a stepped tailor-made e-tool that patients can use to get therapeutic advice between consultations with their GP; it can aid doctors by providing them with diagnostic advice. A randomised controlled trial (RCT) with a parallel 1:1 group allocation and 1-year follow-up was undertaken between December 2013 and October 2015 to compare care using PsyScan with usual care for psychological problems.

\section{Participants}

PsyScan was developed and evaluated by the researchers in the Eindhoven

the Netherlands.

E-mail: luc.giddingamaastrichtuniversity.nl Submitted: 9 April 2017; Editor's response: 8 May 2017; final acceptance: 15 August 2017. CBritish Journal of General Practice

This is the full-length article (published online 19 Dec 2017) of an abridged version published in print. Cite this version as: Br J Gen Pract 2017; DOI: https://doi.org/10.3399/bjgp17X694109 


\section{How this fits in}

GPs play an important role in diagnosing psychological problems and commencing appropriate management for patients who experience them; however, they face some difficulties and need support. To offer this support, PsyScan was developed by the authors, along with a multidisciplinary team that also included patients. In this randomised controlled trial with 336 participants, care using PsyScan was associated with better symptom reduction, better quality of life, and comparable healthcare costs, when compared with usual care. As such, it has shown that PsyScan can be a helpful and cost-effective tool in the diagnosis and management of patients with psychological problems in general practice.

Corporation of Primary Health Care Centres (Stichting Gezondheidscentra Eindhoven [SGE]), which included 10 multidisciplinary care centres with 44 GPs, offering primary care to approximately 70000 registered patients; this constituted about one-third of the population of Eindhoven, which is the fifth largest city in the Netherlands. In the Netherlands, GPs are gatekeepers in primary care; patients can only consult a specialist after referral from a GP.

People who were registered with SGE were eligible if they consulted their GP and met the following inclusion criteria:

- had (suspected) psychological problems;

- were aged $\geq 18$ years

- were able to consent;

- had adequate understanding of the Dutch language;

- were able to receive e-mail and use PsyScan at home.

Patients were excluded if they:

- had clear and treatable somatic causes of symptoms;

- had acute distress or danger leither physically or mentally that warranted immediate action from the GP) ; or

- gave no written informed consent.

\section{Randomisation}

Randomisation using the sequentially numbered, opaque, sealed-envelope method took place during the initial consultation, before participants gave informed consent, so the study did not cause any delay in patient care. ${ }^{28}$ Block randomisation (block size 16) was applied. All GPs received a folder with eight envelopes leading to intervention and eight to the control condition, randomly sequenced.

After the GPs explained the study, checked eligibility criteria, and the eligible patient consented to participate, an envelope was opened, which contained study information, a brief consent form, a detailed consent form, and a registration form. Patients were asked to sign the brief consent form immediately and to return the detailed consent form after 3 days; this ensured they had ample time to think seriously about participating in the study. The brief consent form and registration form were immediately faxed to the researchers, after which they registered the intervention group participants in PsyScan. Control group participants continued to receive usual care after opening the envelope. Patients who did not return the detailed consent form were not followed up and were excluded from the study.

Crossover of control participants was not possible because they were not able to log onto PsyScan. Due to the nature of the intervention, participants and care providers were not blinded for group allocation.

\section{PsyScan intervention}

Information on the development of PsyScan is available from the authors on request. Intervention group participants immediately received a follow-up appointment for 1 week later. On the same day, they received an e-mail to log on to PsyScan. Once logged on, they filled in the three-question distress screener. ${ }^{29}$ If their score was positive ( $>3$ ), participants were asked to complete the Four-Dimensional Symptom Questionnaire (4DSQ), a 50-item questionnaire designed to differentiate between stress, depression, anxiety, and somatisation, and to explore severity. ${ }^{30,31}$ If their score was not positive they received on-screen information that at this moment PsyScan did not indicate any psychological problems but that it was still advisable to have the follow-up appointment in 1 week with the GP to further discuss the matter. The $4 D S Q$ was validated in primary care and is recommended for use in the guidelines of Dutch GPs. ${ }^{32-34}$

The authors developed an algorithm to translate the possible scores on the $4 D S Q$ into:

- diagnostic advice, given as possible International Classification of Primary Care (ICPC) codes; and

- therapeutic advice, given as possible treatment or referral options. 
Participants received on-screen, individualised information about symptoms and possible treatments, based on Dutch guidelines.

Additionally, a cause inventory was administered, consisting of questions that participants could answer in their own words. These addressed areas that could be the cause of symptoms, such as family and friends, work, finances, housing, physical symptoms, memory, mourning, eating and drinking, addictions, impulse control and anger, sexuality, loneliness, mobility, social media stress, or other. Here, participants could also indicate goals related to possible treatment(s); another person, such as a partner or relative, could also give additional information.

The $4 D S Q$ results, the cause inventory, and diagnostic and therapeutic advice were automatically transferred to the participant's dossier in the EMR held by the GP. During the scheduled follow-up appointment, the participant and GP discussed the results and initiated management. The participants were asked not to initiate any therapies before the follow-up appointment with the GP because the choice was wanted for therapy to be a shared decision between GP and patient.

\section{Outcomes}

Main study parameter and endpoint. The proportion of participants that achieved a decrease of $\geq 50 \%$ on the Symptom Checklist-90-Revised (SCL-90-R) was measured after 1 year. ${ }^{35}$ SCL-90-R scores can range from 90 to 450 ; higher scores indicate higher symptom levels.

Secondary study parameters and endpoints. The following were evaluated:
- SCL-90-R scores after 3, 6, and 12 months;

- QOL after 3, 6, and 12 months. This was assessed using the EuroQol 5 Dimensions 5 Levels (EQ-5D-5L) questionnaire. EQ-5D-5L visual analogue scale (VAS) scores can range from 0 to 100; higher scores indicate higher QOL. Answers to the five $E Q-5 D-5 L$ questions were converted to index values. ${ }^{36}$ Dutch EQ-5D$5 \mathrm{~L}$ index values can range from -0.329 to 1.000; higher values indicate higher QOL;

- participant satisfaction with the care they received. This was scored after 3,6 , and 12 months using the Patient Assessment of Chronic Illness Care (PACIC). ${ }^{37}$ The PACIC consists of 20 items and the overall summary score can range from 1 to 5 , with higher scores indicating higher levels of satisfaction;

- Psyscan results and percentages of participants that received an ICPC code and were treated/referred in accordance with the PsyScan advice;

- relevant care parameters. These were registered by GPs during followup and extracted from the EMR to monitor: changes in referrals to psychology and psychiatry; the use of minimal interventions, including brief counselling, bibliotherapy, mindfulness, psychoeducation, problem-solving therapy, or referral to a social worker; physical exercise therapies, including running therapy, physiotherapy, manual therapy, and Cesar therapy; and pharmaceutical therapy with anxiolytics, hypnotics and sedatives, antidepressants, and psychiatric medication overall lall Anatomical Therapeutic Chemical classification ' $N$ ' groups combined);

\section{Table 1. Secondary EMR outcomes: results from logistic regression analyses, adjusting for age, sex, socioeconomic status, prior psychological symptoms, and baseline SCL-90-R score $(n=336)$}

\begin{tabular}{|c|c|c|c|c|c|}
\hline Outcome $^{a}$ & Intervention group, $n(\%)$ & Control group, $n(\%)$ & Odds ratio & $95 \% \mathrm{Cl}$ & $\boldsymbol{P}$-value \\
\hline Total & $176(100)$ & $160(100)$ & & & \\
\hline Participants with psychology referral & $30(17)$ & $16(10)$ & 1.8 & 0.9 to 3.5 & 0.08 \\
\hline Participants with psychiatry referral & $21(12)$ & $9(6)$ & 2.4 & 1.0 to 5.5 & 0.05 \\
\hline Participants with minimal intervention & $72(41)$ & 60 (38) & 1.1 & 0.7 to 1.7 & 0.78 \\
\hline Participants with exercise & $14(8)$ & $9(6)$ & 1.3 & 0.5 to 3.2 & 0.55 \\
\hline Participants prescribed anxiolytics & $24(14)$ & $28(18)$ & 0.6 & 0.3 to 1.2 & 0.15 \\
\hline Participants prescribed hypnotics and sedatives & $16(9)$ & $27(17)$ & 0.5 & 0.2 to 0.9 & 0.02 \\
\hline Participants prescribed antidepressants & $18(10)$ & $18(11)$ & 0.9 & 0.5 to 1.9 & 0.85 \\
\hline Participants prescribed psychiatric medication & 65 (37) & $65(41)$ & 0.8 & 0.5 to 1.3 & 0.37 \\
\hline
\end{tabular}

Total values are different because participants could have more than one outcome. EMR = electronic medical record. SCL-90-R=Symptom Checklist-90-Revised. 
- healthcare consumption in primary and secondary care, use of prescribed and over-the-counter medication, absenteeism, and productivity loss to perform a cost-effectiveness analysis. The Trimbos/iMTA questionnaire for Costs Associated with Psychiatric Illness (TiC-P) was completed after 3, 6, 9, and 12 months, and EMR parameters referred to in Table 1.38 An incremental costeffectiveness ratio (ICER) was calculated based on the primary outcome and mean total costs.

\section{Sample size}

A successful treatment result was defined as a decrease of $\geq 50 \%$ in SCL-90-R score after 1 year. ${ }^{17,39-47}$ It was assumed that a successful result would occur in $70 \%$ of participants receiving usual care and a difference of $10 \%$ was considered to be clinically relevant by the study team. Assuming a significance level of $\alpha=0.05$ and power of 0.80 , at least 289 participants
Figure 1. Study flowchart. $S C L-90-R=$ Symptom Checklist-90-Revised. were required based on the $\chi^{2}$ test. Taking a $10 \%$ dropout rate into account, according to Rigby and Vail's statistical methods, ${ }^{48}$ it was calculated that 322 participants had to be included per group.

\section{Statistical methods}

A logistic regression analysis was performed to evaluate the primary outcome. As well as the complete case analysis, where only participants with no missing values were included, multiple imputation for chained equations was also performed, using fully conditional specification to account for missing values. In this way, 40 complete datasets were created; group (intervention/ control), age, sex, socioeconomic status, prior psychological problems, and baseline SCL-90-R scores were used as predictors.

To assess longitudinal effects, linear mixed models with time, group, and group*time as fixed factors were used for numerical secondary outcomes that were measured repeatedly. This analysis method accounts for baseline differences and dependency between repeated measures within the same participant, where an unstructured covariance structure was used for the repeated measures. A likelihood-based approach was used for missing outcome values in these linear mixed models. Categorical secondary outcomes, with only one measurement during follow-up, were analysed with logistic regression analyses, whereas continuous secondary outcomes were measured with linear regression analyses.

Socioeconomic status based on postal codes was derived from status scores from the Netherlands Institute for Social Research; 49,50 higher scores indicate higher socioeconomic status. Prior psychological symptoms were defined as the patient having an episode of any chapter ' $P$ ' ('psychological') ICPC code between July 2003 and the study inclusion date recorded in their EMR.

Sensitivity analyses were performed to assess the influence of clustering of participants in centres and of individual GPs, using generalised estimating equations for categorical outcomes and linear mixed models for numerical outcomes. Statistical procedures were performed by two researchers using IBM SPSS (version 21.0), during which they were blinded for group allocation. The level of statistical significance was set at $P \leq 0.05$.

\section{RESULTS}

GPs randomised 535 patients from December 2013 through to September 2014. 
Table 2. Participants' baseline characteristics $(n=336)$

\begin{tabular}{lcc} 
& Intervention group & \multicolumn{1}{c}{ Control group } \\
\hline Total, $n$ & 176 & 160 \\
\hline Female, $n(\%)$ & $123(70)$ & 109 (68) \\
\hline Mean age at inclusion, years (SD) & $42.4(13.8)$ & $42.9(14.1)$ \\
\hline Mean socioeconomic status score (SD) & $0.174(1.012)$ & $-0.137(1.003)$ \\
\hline With prior psychological symptoms or disorders, $n(\%)$ & $123(70)$ & 108 (68) \\
\hline Mean baseline SCL-90-R score (SD) & $178.7(54.1)$ & $173.5(57.1)$ \\
\hline Mean baseline EQ-5D-5L VAS score (SD) & $61.6(19.0)$ & $65.0(16.9)$ \\
\hline Mean baseline EQ-5D-5L index (SD) & $0.699(0.191)$ & $0.716(0.191)$ \\
\hline EQ-5D-5L = EuroQol 5 Dimensions 5 Levels. SCL-90-R= Symptom Checklist-90-Revised. SD = standard deviation. \\
VAS = visual analogue scale.
\end{tabular}

Figure 2. Estimated means and $95 \%$ Cls based on linear mixed model analyses of SCL-90-R scores $(n=336)$. $S C L-90-R=$ Symptom Checklist-90-Revised.
Of these, 199 were excluded either because they did not return the detailed consent form or because of other exclusion criteria. Of the remaining 336, 176 participants were included in the intervention group and 160 in the control group (Figure 1). Twenty-five of those in the intervention group did not use PsyScan, either due to technical difficulties or severe psychological problems. In total, $289(86 \%)$ of the participants returned the baseline SCL-90-R, 158 (47\%) returned it at 3 months, $128(38 \%)$ at 6 months, and 205 (61\%) at 12 months. Participants' baseline

\section{Outcomes}

The results of all regression and mixedcharacteristics are shown in Table 2.

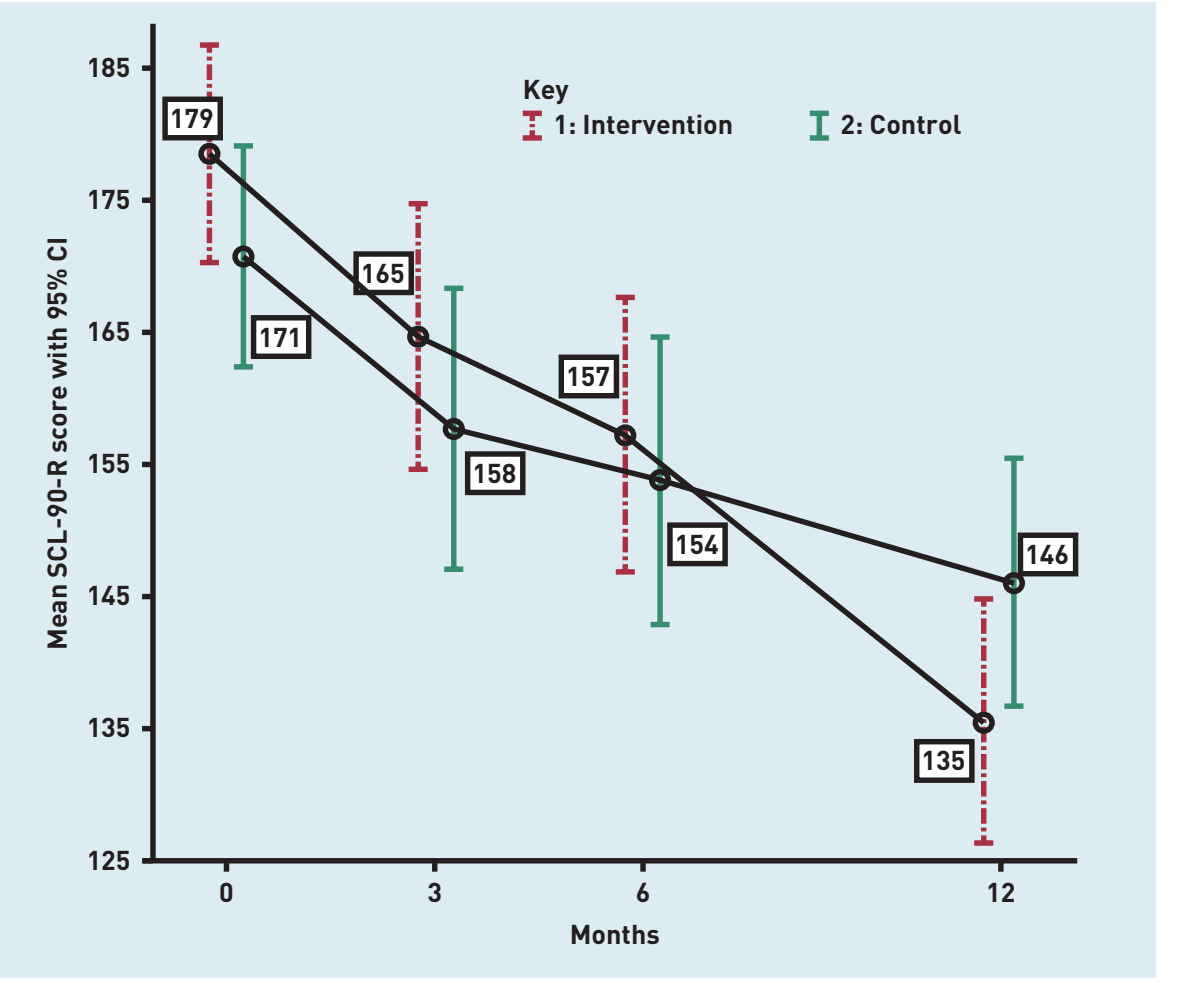

model analyses - adjusted for age, sex socioeconomic status, prior psychological symptoms, and baseline SCL-90-R score - are presented here; crude analyses are available from the authors on request.

Main study parameter and endpoint. In total, 196 participants were included in the logistic regression complete case analysis for the primary outcome (102 participants from the intervention group and 94 from the control group). Of the 102 intervention participants, 61 (60\%) achieved a successful treatment result, compared with 30 (32\%) in the control group lodds ratio [OR] 3.1, $95 \%$ confidence interval $[\mathrm{Cl}]=1.7$ to 5.7 $P<0.001$ ). To account for missing values, multiple imputation was performed; this produced an OR of $2.7(95 \% \mathrm{Cl}=1.5$ to 4.8 , $P=0.002$ ).

Sensitivity analyses, which were performed to test the influence of centres and individual GPs, showed similar results for both the adjusted and crude analyses.

Secondary study parameters and endpoints. All 336 participants were included in the adjusted linear mixed model analyses (Figure 2), which resulted in a statistically significant difference in the mean decrease of the SCL-90-R score after 12 months between the groups (mean difference $-18.3,95 \% \mathrm{Cl}=-32.0$ to -4.7 , $P=0.009$, Table 3).

EQ-5D VAS scores showed the largest difference after 6 months (mean difference 6.3, $95 \% \mathrm{Cl}=1.2$ to $11.4, \quad P=0.01)$, whereas mean index values showed the greatest difference after 12 months (mean difference $0.076,95 \% \mathrm{Cl}=0.015$ to 0.136 , $P=0.01$ ) (Table 3). No statistically significant differences were observed in the PACIC scores (Table 3). Sensitivity analyses showed similar results for adjusted and crude analyses.

PsyScan and healthcare parameters. In total, 151 intervention participants completed PsyScan. Of these, 22 had a negative distress screener score.

In the intervention group, GPs actions and PsyScan advice were in accordance with each other in terms of ICPC coding in $45 \%(n=68)$ of cases, medication in $93 \%$ ( $n=141)$ of cases, and treatment/referral in $97 \%(n=147)$ of cases (Table 4).

Referral rates to psychology or psychiatry were $17 \%(n=30)$ and $12 \%(n=21)$ in the intervention group, and $10 \%(n=16)$ and $6 \%(n=9)$ in the control group respectively (Table 1). Psychiatric medication was prescribed to $<42 \%$ of participants. In the 
intervention group, all non-pharmaceutical therapies were deployed more often and all pharmaceutical therapies less often than in the control group (Table 1).

Cost-effectiveness analysis. All in all, 174 participants completed the TiC-P and SCL-90-R, and were included in the cost-effectiveness analysis based on the primary outcome. The mean 1-year cost per participant in the intervention group was $€ 13622$ (standard deviation [SD] €16 398) and€12 487 (SD€14 862) per control. A linear regression analysis showed no statistically significant influence of group allocation on the mean 1 -year costs $(\beta=-0.03, P=0.71$, $\mathrm{R}^{2}=0.05$, Table 5).

Of these 174 participants, 58\% $(n=55)$ of the intervention group and $38 \%(n=30)$ of the control group achieved a successful treatment result $(\mathrm{OR} 2.2,95 \% \mathrm{Cl}=1.1$ to 4.1, $P=0.02$, data not shown). This resulted in an ICER of 57.0, indicating that, for every $1 \%$ of patients that achieved a successful treatment result based on care with PsyScan, the cost was $€ 57.00$ more per year than the cost of usual care.

\section{DISCUSSION}

\section{Summary}

PsyScan generated clinically relevant and statistically significant effects: intervention participants had statistically significantly higher chances of achieving symptom reduction of $\geq 50 \%$ after 1 year and reported better QOL scores. Care based on PsyScan was associated with comparable costs in the control group. GPs generally acted according to the advice generated by the e-tool.

\section{Strengths and limitations}

A bottom-up approach, involving patients and all relevant disciplines, was used to develop PsyScan. This was crucial and made it easier to motivate GPs to both use the e-tool and participate in the research. This strength was illustrated by the high accordance of GPs' actions with the PsyScan treatment advice. Accordance with the PsyScan's registration/ICPC advice was lower (45\%) but this might be explained by the timing in relation to the initial consultation because Dutch GPs are used to registering their actions episodeoriented (that is, attributing actions to an ICPC code episode). Therefore, whenever patients consulted their GP, the GP ascribed an ICPC code to the consultation, before the PsyScan results arrived, as opposed to starting treatment or referral, which was done after obtaining the results.

Another strength is that PsyScan differentiates between problems rather than focusing on one distinct psychological issue. It also provides both diagnostic

Table 3. Secondary questionnaire outcomes: results from linear mixed model analyses, adjusting for age, sex, socioeconomic status, prior psychological symptoms, and baseline SCL-90-R score $(n=336)$

\begin{tabular}{|c|c|c|c|c|c|}
\hline Outcome & $\begin{array}{l}\text { Intervention group, } \\
\text { mean (SE) }\end{array}$ & $\begin{array}{c}\text { Control group, } \\
\text { mean (SE) }\end{array}$ & Corrected mean difference & $95 \% \mathrm{Cl}$ & $P$-value \\
\hline \multicolumn{6}{|c|}{ SCL-90-R, mean total score } \\
\hline Baseline & $179(4.1)$ & $171(4.2)$ & 7.8 & -3.2 to 18.8 & 0.17 \\
\hline 3 months & $165(5.1)$ & $158(5.4)$ & -0.8 & -11.0 to 9.5 & 0.88 \\
\hline 6 months & $157(5.3)$ & $154(5.5)$ & -4.3 & -15.5 to 6.9 & 0.45 \\
\hline 12 months & 135 (4.7) & $146(4.8)$ & -18.3 & -32.0 to -4.7 & 0.009 \\
\hline \multicolumn{6}{|c|}{ EQ-5D-5L, mean VAS score ${ }^{a}$} \\
\hline Baseline & $61.5(1.1)$ & $66.0(1.2)$ & -4.5 & -7.6 to -1.5 & 0.004 \\
\hline 3 months & $68.6(1.5)$ & $69.6(1.7)$ & 3.5 & -1.0 to 8.1 & 0.13 \\
\hline 6 months & $71.5(1.7)$ & $69.7(1.8)$ & 6.3 & 1.2 to 11.4 & 0.01 \\
\hline 12 months & $71.6(2.1)$ & 70.3 (2.3) & 5.8 & -0.3 to 11.9 & 0.06 \\
\hline \multicolumn{6}{|c|}{ EQ-5D-5L, mean index ${ }^{a}$} \\
\hline Baseline & $0.706(0.011)$ & $0.737(0.011)$ & -0.031 & -0.061 to -0.001 & 0.04 \\
\hline 3 months & 0.749 (0.018) & $0.760(0.020)$ & 0.020 & -0.032 to 0.071 & 0.45 \\
\hline 6 months & $0.778(0.018)$ & 0.775 (0.019) & 0.035 & -0.017 to 0.086 & 0.19 \\
\hline \multicolumn{6}{|c|}{ PACIC, mean score } \\
\hline 3 months & $2.9(0.0)$ & $2.9(0.0)$ & 0.1 & -0.0 to 0.2 & 0.14 \\
\hline 6 months & $2.8(0.1)$ & $2.9(0.1)$ & -0.1 & -0.4 to 0.2 & 0.38 \\
\hline 12 months & $2.8(0.1)$ & $3.0(0.1)$ & -0.3 & -0.5 to 0.0 & 0.08 \\
\hline
\end{tabular}

aThe adjusted mean differences after 3, 6, and 12 months were adjusted for the corresponding difference in mean baseline score. EQ-5D-5L = EuroQol 5 Dimensions 5 Levels. $P A C I C=$ Patient Assessment of Chronic Illness Care. SCL-90-R=Symptom Checklist-90-Revised. SE = standard error. VAS = visual analogue scale. 
Table 4. PsyScan results for intervention group $(n=176)$

\begin{tabular}{|c|c|c|}
\hline & & $\begin{array}{r}\text { Possible } \\
\text { scores }^{a}\end{array}$ \\
\hline Participants completed PsyScan, $n(\%)$ & $151(86)$ & $\mathrm{n} / \mathrm{a}$ \\
\hline Mean distress screener score (SD) & $4.8(1.2)$ & $0-6$ \\
\hline Participants with positive distress screener score (>3), $n(\%)$ & 129 (85) & $\mathrm{n} / \mathrm{a}$ \\
\hline Mean $4 D S Q$ stress score (SD) & $24.0(6.3)$ & $0-32$ \\
\hline Mean 4DSQ depression score (SD) & $5.0(4.0)$ & $0-12$ \\
\hline Mean 4DSQ anxiety score (SD) & 6.7 (5.5) & $0-24$ \\
\hline Mean 4DSQ somatisation score (SD) & $13.9(7.2)$ & $0-32$ \\
\hline Participants had ICPC coding in accordance with PsyScan advice, $n(\%)$ & $68(45)$ & $\mathrm{n} / \mathrm{a}$ \\
\hline Participants had medication in accordance with PsyScan advice, $n$ (\%) & 141 (93) & $\mathrm{n} / \mathrm{a}$ \\
\hline Participants had treatment/referral in accordance with PsyScan advice, $n(\%)$ & 147 (97) & $\mathrm{n} / \mathrm{a}$ \\
\hline
\end{tabular}

information and therapeutic options, and was linked to EMRs.

Use of an e-tool, as opposed to a paper questionnaire, offers important advantages as it allows for relevant information to be exchanged between patients and healthcare providers without taking up extra time..$^{51,52}$ In the case of PsyScan, additional benefits, including automatically generated scores and advice, and no duplication of data by healthcare providers, were incorporated. Unlike freely available e-tools Iwhich have no standard terms of use that are monitored within the practice), PsyScan was integrated into general practice and supervised by GPs; this ensured that patients received proper advice on how to use it and appropriate follow-up.

The end of the study period was decided on for pragmatic and financial reasons.
A major limitation was the loss to followup; this was high, despite efforts from the study team to prevent dropout. Although participating in scientific studies can be difficult for any patient, it is possible that participants in this study found it particularly hard, due to their psychological problems sometimes preventing them from completing the questionnaires. Substantial loss to follow-up is a common problem in psychological health research; ${ }^{12,53,54}$ however, in this study the rate of loss to follow-up was similar in both groups, which allowed the authors to account for it using multiple imputation and linear mixed models (likelihood approach).

GPs and participants could not be blinded. This may have caused performance bias; that is, participants and care providers in the intervention group could have been more motivated to complete the questionnaires, and adhere to the recommendations. Additionally, GPs could have applied skills they learned from PsyScan to their patients who were in the control group. The authors feel, however, that this learning bias would be small for a variety of reasons. First, PsyScan consists of technical elements Ifor example, the automated generation of scores and diagnostic and therapeutic advice) that would have been difficult to replicate without the software. In addition, the mean number of patients in the intervention group per GP was no more than four; considering this, and the extent of the diversity in psychological problems in general practice, it is likely that there was little opportunity for GPs to discern patterns to learn that they could then apply to patients in the control group.

As the severity of psychological problems

Table 5. Generated costs: results from linear regression analyses, adjusting for age, sex, socioeconomic status, prior psychological symptoms and baseline SCL-90-R score $(n=174)$

\begin{tabular}{|c|c|c|c|c|c|}
\hline & \multirow{2}{*}{$\begin{array}{c}\text { Intervention group, } n=95 \\
\text { Mean 1-year cost } \\
\text { per participant, € (SD) }\end{array}$} & \multirow{2}{*}{$\begin{array}{c}\text { Control group, } n=79 \\
\text { Mean 1-year cost } \\
\text { per participant, } € \text { (SD) }\end{array}$} & \multirow[b]{2}{*}{$\beta$} & \multirow[b]{2}{*}{$P$-value } & \multirow[b]{2}{*}{$\mathbf{R}^{2}$} \\
\hline & & & & & \\
\hline Healthcare consumption & 2277 (2449) & 2542 (2882) & 0.05 & 0.48 & 0.07 \\
\hline Use of medication & $176(1016)$ & 375 (1560) & 0.06 & 0.41 & 0.03 \\
\hline Paid work absenteeism, short term ( $\leq 4$ weeks) & $814(2360)$ & 1519 (3199) & 0.15 & 0.05 & 0.06 \\
\hline Paid work absenteeism, long term (>4 weeks) & 3225 (7416) & 1778 (5568) & -0.10 & 0.19 & 0.02 \\
\hline Productivity loss, paid work & 3832 (8035) & 2029 (4701) & -0.12 & 0.11 & 0.09 \\
\hline Productivity loss, unpaid work & 3301 (8458) & $4244(11013)$ & 0.04 & 0.59 & 0.04 \\
\hline Totala & 13622 (16 398) & 12487 (14862) & -0.03 & 0.71 & 0.05 \\
\hline
\end{tabular}

${ }^{a}$ Total values are different because of rounding. $\beta=$ standardised regression coefficient. $S C L-90-R=$ Symptom Checklist-90-Revised. $S D=$ standard deviation. 
at baseline was relatively low, it might have been more difficult to achieve a successful treatment result lit is more difficult to reduce low scores by $\geq 50 \%$ ). As such, the assumption that $80 \%$ of the intervention group and $70 \%$ of control group participants would achieve a successful treatment result was, perhaps, too optimistic; however a statistically significant result was still obtained.

PsyScan was associated with more clinically relevant and statistically significant patient recovery without being associated with statistically significantly higher costs. However, a substantial part of the cost data was missing, so care must be taken when interpreting the cost-effectiveness results.

\section{Comparison with existing literature}

In the intervention group, patient recovery was ongoing throughout follow-up, whereas, in the group receiving usual care, it appeared to weaken. Hypothetically, PsyScan provided information and guidance to GPs, allowing the offer of care with longer-lasting effects. The positive effects of PsyScan were due to patients being managed more appropriately. The benefit of PsyScan was also illustrated by feedback from several GPs and participants, who stated that it resulted in a better understanding between patient and doctor; this is supported by literature showing that good patient-doctor communication improves outcomes. ${ }^{55}$

Similarly, PsyScan may have helped GPs and participants to assess a broader range of symptoms, whereas usual care might focus on some prominent problems; for example, somatic problems are known to distract from the psychological problems that cause them. ${ }^{4}$ Furthermore, many individuals have trouble expressing psychological problems to GPs; as web-based assessments require less social interaction, people may divulge more personal information than they do in face-to-face consultations. ${ }^{56-60}$

Dutch guidelines urge GPs to be reticent when prescribing psychiatric medication and encourage them to make greater use of non-pharmaceutical alternatives, especially in the case of moderate problems. ${ }^{32-34}$ This may have resulted in relatively low prescription rates compared with other settings; ${ }^{61}$ anxiolytics, hypnotics, and sedatives formed no part of the PsyScan advice and, accordingly, were prescribed substantially less often for intervention participants than for control group participants in this study.

\section{Implications for research and practice}

From literature and preliminary studies carried out in general practice, it is known that primary care providers and patients perceive a need for pragmatic, comprehensive, and integrated tools to use in psychological care. ${ }^{62}$ Not all GPs welcome tools (electronic or otherwise); some may prefer to rely on experience and clinical judgement, which are undoubtedly among the most powerful tools they can use. ${ }^{63}$ Nevertheless, this study has shown that PsyScan can be a beneficial supplement to create more uniformity, it can provide more useful information with less effort, and it includes elements for every GP. Some GPs will only want to use the digital administration of the $4 D S Q$, diagnostic and therapeutic advice, or a cause inventory; moreover, different elements are of different value for different patients. However, PsyScan has demonstrated that it can be highly effective in structuring individualised care to patients in general practice.

This study has demonstrated PsyScan's clinical effects and associated costs. Future research should be undertaken to show how it can be implemented in different settings and to further assess its effects and the cost-effectiveness of using this e-tool.

\section{Ethical approval}

This trial was approved by the Medical Ethical Committee of Maastricht University Medical Center (reference: NL44597.068.13/13-3034) and registered in the ClinicalTrials.gov database (NCT01971307).

\section{Provenance}

Freely submitted; externally peer reviewed.

\section{Competing interests}

All the authors have contributed to the development of PsyScan but none has economic interests in PsyScan.

\section{Discuss this article}

Contribute and read comments about this article: bjgp.org/letters 


\section{REFERENCES}

1. World Health Organization. The global burden of disease: 2004 update. 2008. http://www.who.int/healthinfo/global_burden_disease/GBD_ report_2004update_full.pdf?ua=1 laccessed 19 Sep 2017).

2. World Health Organization. Mental health action plan 2013-2020. 2013. http:// apps.who.int/iris/bitstream/10665/89966/1/9789241506021_eng.pdf?ua=1 laccessed 19 Sep 2017).

3. Alonso J, Angermeyer MC, Bernert S, et al. Prevalence of mental disorders in Europe: results from the European Study of the Epidemiology of Mental Disorders (ESEMeD) project. Acta Psychiatr Scand Suppl 2004; (420): 21-27.

4. Timonen M, Liukkonen T. Management of depression in adults. BMJ 2008; 336(7641): 435-439.

5. Young AS, Klap R, Sherbourne CD, Wells KB. The quality of care for depressive and anxiety disorders in the United States. Arch Gen Psychiatry 2001; 58(1): 55-61.

6. Mitchell AJ, Vaze A, Rao S. Clinical diagnosis of depression in primary care: a meta-analysis. Lancet 2009; 374(9690): 609-619.

7. Hegarty K, Gunn J, Blashki G, et al. How could depression guidelines be made more relevant and applicable to primary care? A quantitative and qualitative review of national guidelines. Br J Gen Pract 2009; DOI: https://doi. org/10.3399/bjgp09X420581.

8. Cepoiu M, McCusker J, Cole MG, et al. Recognition of depression by nonpsychiatric physicians: a systematic literature review and meta-analysis. $J$ Gen Intern Med 2008; 23(1): 25-36.

9. Kroenke K, Spitzer RL, Williams JB, et al. Anxiety disorders in primary care: prevalence, impairment, comorbidity, and detection. Ann Intern Med 2007; 146(5): 317-325.

10. Bet PM, Hugtenburg JG, Penninx BW, et al. Treatment inadequacy in primary and specialized care patients with depressive and/or anxiety disorders. Psychiatry Res 2013; 210(2): 594-600

11. Fernández A, Haro JM, Martinez-Alonso M, et al. Treatment adequacy for anxiety and depressive disorders in six European countries. Br J Psychiatry 2007; 190: 172-173

12. Archer J, Bower P, Gilbody S, et al. Collaborative care for depression and anxiety problems. Cochrane Database Syst Rev 2012; 10: CD006525.

13. Sinnema H, Franx G, Spijker J, et al. Delivering stepped care for depression in general practice: results of a survey amongst general practitioners in the Netherlands. Eur J Gen Pract 2013; 19(4): 221-229.

14. Adli M, Bauer M, Rush AJ. Algorithms and collaborative-care systems for depression: are they effective and why? A systematic review. Biol Psychiatry 2006; 59(11): 1029-1038.

15. Bijl D, van Marwijk HW, de Haan M, et al. Effectiveness of disease management programmes for recognition, diagnosis and treatment of depression in primary care. Eur J Gen Pract 2004; 10(1): 6-12.

16. Franx G, Meeuwissen JA, Sinnema $H$, et al. Quality improvement in depression care in the Netherlands: the Depression Breakthrough Collaborative. A quality improvement report. Int J Integr Care 2009; 9: e84.

17. Neumeyer-Gromen A, Lampert T, Stark K, Kallischnigg G. Disease management programs for depression: a systematic review and metaanalysis of randomized controlled trials. Med Care 2004; 42(12): 1211-1221.

18. van Straten A, Seekles W, van 't Veer-Tazelaar NJ, et al. Stepped care for depression in primary care: what should be offered and how? Med J Aust 2010; 192(11 Suppl): S36-S39.

19. Cain RA. Navigating the Sequenced Treatment Alternatives to Relieve Depression (STAR*D) study: practical outcomes and implications for depression treatment in primary care. Prim Care 2007; 34(3): 505-519.

20. Serrano N, Molander R, Monden K, et al. Exemplars in the use of technology for management of depression in primary care. WMJ 2012; 111(3): 112-118.

21. Seekles W, van Straten A, Beekman A, et al. Stepped care treatment for depression and anxiety in primary care: a randomized controlled trial. Trials 2011; 12(1): 171

22. Donker T, Comijs H, Cuijpers $P$, et al. The validity of the Dutch K10 and extended K10 screening scales for depressive and anxiety disorders. Psychiatry Res 2010; 176(1): 45-50.

23. Donker T, van Straten A, Marks I, Cuijpers P. A brief web-based screening questionnaire for common mental disorders: development and validation. $J$ Med Internet Res 2009; 11(3): e19.

24. Farvolden P, McBride C, Bagby RM, Ravitz P. A web-based screening instrument for depression and anxiety disorders in primary care. J Med Internet Res 2003; 5(3): e23.

25. Lin CC, Bai YM, Liu CY, et al. Web-based tools can be used reliably to detect patients with major depressive disorder and subsyndromal depressive symptoms. BMC Psychiatry 2007; 7: 12.

26. Spitzer RL, Williams JB, Kroenke K, et al. Utility of a new procedure for diagnosing mental disorders in primary care. The PRIME-MD 1000 study. JAMA 1994; 272(22): 1749-1756.

27. Gilbody S, Bower P, Fletcher J, et al. Collaborative care for depression: a cumulative meta-analysis and review of longer-term outcomes. Arch Intern Med 2006; 166(21): 2314-2321.

28. Doig GS, Simpson F. Randomization and allocation concealment: a practical guide for researchers. J Crit Care 2005; 20(2): 187-191; discussion 191-193.

29. Braam C, van Oostrom SH, Terluin B, et al. Validation study of a distress screener. J Occup Rehabil 2009; 19(3): 231-237.

30. Terluin B, Brouwers EP, Van Marwijk HW, et al. Detecting depressive and anxiety disorders in distressed patients in primary care; comparative diagnostic accuracy of the Four-Dimensional Symptom Questionnaire (4DSQ) and the Hospital Anxiety and Depression Scale (HADS). BMC Fam Pract 2009; 10: 58 .

31. Terluin B, Van Marwijk HW, Adèr HJ, et al. The Four-Dimensional Symptom Questionnaire (4DSQ): a validation study of a multidimensional self-report questionnaire to assess distress, depression, anxiety and somatization. BMC Psychiatry 2006; 6: 34

32. van Weel-Baumgarten E, van Gelderen G, Grundmeijer H, et al. NHG guideline on major depressive disorder: second revision. [In Dutch]. Huisarts Wet 2012; 55(6): 252-259.

33. van Avendonk MJ, Hassink-Franke LJ, Terluin B, et al. Summarisation of the NHG practice guideline 'Anxiety'. [In Dutch]. Ned Tijdschr Geneeskd 2012; 156(34): A4509.

34. Hassink-Franke LJ, Terluin B, van Heest F, et al. NHG guideline on anxiety: second revision. (In Dutch). Huisarts Wet 2012; 55(2): 68-77.

35. Derogatis LR, Cleary PA. Confirmation of the dimensional structure of the SCL-90: a study in construct validation. J Clin Psychol 1977; 33(4): 981-989.

36. van Hout $B$, Janssen MF, Feng Y-S, et al. Interim scoring for the EQ-5D-5L: mapping the EQ-5D-5L to EQ-5D-3L value sets. Value Health 2012; 15(5): 708-715.

37. Glasgow RE, Wagner EH, Schaefer J, et al. Development and validation of the Patient Assessment of Chronic Illness Care (PACIC). Med Care 2005; 43(5): 436-444.

38. Bouwmans $C$, De Jong $K$, Timman $R$, et al. Feasibility, reliability and validity of a questionnaire on healthcare consumption and productivity loss in patients with a psychiatric disorder (TiC-P). BMC Health Serv Res 2013; 13: 217.

39. Fann JR, Fan MY, Unützer J. Improving primary care for older adults with cancer and depression. J Gen Intern Med 2009; 24(Suppl 2): S417-S424.

40. Hunkeler EM, Meresman JF, Hargreaves WA, et al. Efficacy of nurse telehealth care and peer support in augmenting treatment of depression in primary care. Arch Fam Med 2000; 9(8): 700-708.

41. Katon W, Von Korff M, Lin E, et al. Collaborative management to achieve treatment guidelines. Impact on depression in primary care. JAMA 1995; 273(13): 1026-1031.

42. Katzelnick DJ, Simon GE, Pearson SD, et al. Randomized trial of a depression management program in high utilizers of medical care. Arch Fam Med 2000; 9(4): 345-351.

43. Kayser S, Bewernick BH, Grubert C, et al. Antidepressant effects, of magnetic seizure therapy and electroconvulsive therapy, in treatment-resistant depression. J Psychiatr Res 2011; 45(5): 569-576.

44. Simon GE, Von Korff M, Rutter C, Wagner E. Randomised trial of monitoring, feedback, and management of care by telephone to improve treatment of depression in primary care. BMJ 2000; 320(7234): 550-554.

45. Unützer J, Katon W, Callahan CM, et al. Collaborative care management of late-life depression in the primary care setting: a randomized controlled trial. JAMA 2002; 288(22): 2836-2845.

46. Von Korff M, Katon W, Bush T, et al. Treatment costs, cost offset, and costeffectiveness of collaborative management of depression. Psychosom Med 1998; 60(2): 143-149.

47. Katon W, Robinson P, Von Korff M, et al. A multifaceted intervention to improve treatment of depression in primary care. Arch Gen Psychiatry 1996. 53(10): 924-932. 
48. Rigby AS, Vail A. Statistical methods in epidemiology. II: A commonsense approach to sample size estimation. Disabil Rehabil 1998; 20(11): 405-410.

49. Netherlands Institute for Social Research. Status scores in the Netherlands 1998-2014. The Hague: SCP, 2014.

50. Knol F. Status development in neighbourhoods in the Netherlands 1998-2010. [In Dutch]. The Hague: SCP, 2012.

51. Buchanan T. Online assessment: desirable or dangerous? Prof Psychol Res Pr 2002; 33(2): 148-154.

52. Emmelkamp PM. Technological innovations in clinical assessment and psychotherapy. Psychother Psychosom 2005; 74(6): 336-343.

53. Kendrick T, El-Gohary M, Stuart B, et al. Routine use of patient reported outcome measures (PROMs) for improving treatment of common mental health disorders in adults. Cochrane Database Syst Rev 2016; 7: CD011119.

54. Williams JW Jr, Gerrity M, Holsinger T, et al. Systematic review of multifaceted interventions to improve depression care. Gen Hosp Psychiatry 2007; 29(2): 91-116.

55. Hassan I, McCabe R, Priebe S. Professional-patient communication in the treatment of mental illness: a review. Commun Med 2007; 4(2): 141z-152.

56. Prior L, Wood F, Lewis G, Pill R. Stigma revisited, disclosure of emotional problems in primary care consultations in Wales. Soc Sci Med 2003; 56(10):
2191-2200

57. Cape J, McCulloch Y. Patients' reasons for not presenting emotional problems in general practice consultations. Br J Gen Pract 1999; 49(448): 875-879.

58. Stromberg R, Wernering E, Aberg-Wistedt A, et al. Screening and diagnosing depression in women visiting GPs' drop in clinic in primary health care. BMC Fam Pract 2008; 9: 34

59. Richman WL, Kiesler S, Weisband S, Drasgow F. A meta-analytic study of social desirability distortion in computer administered questionnaires, traditional questionnaires, and interviews. J Appl Psychol 1999; 84: 754-775.

60. Wallace P. The psychology of the internet. Cambridge: Cambridge University Press, 1999.

61. Ilyas S, Moncrieff J. Trends in prescriptions and costs of drugs for mental disorders in England, 1998-2010. Br J Psychiatry 2012; 200(5): 393-398.

62. Gidding L, Spigt M, Brouwer E, et al. Experiences of general practitioners, practice nurses, psychologists and patients with stepped collaborative care for depression: a focus group study in a large primary healthcare organization. Eur J Pers Cent Healthc 2014; 2(2): 170-178. http://bjll.org/index.php/ejpch/ issue/view/100

63. Dowrick C, Leydon GM, McBride A, et al. Patients' and doctors' views on depression severity questionnaires incentivised in UK quality and outcomes framework: qualitative study. BMJ 2009; 338: b663. 